\title{
Mechanical and Thermal Properties of PLA Biocomposites Reinforced by Coir Fibers
}

\author{
Zhihui Sun, Li Zhang, Duoping Liang, Wei Xiao, and Jing Lin
}

Harbin University of Commerce, Harbin 150028, China

Correspondence should be addressed to Zhihui Sun; sunzhihui1962@163.com

Received 1 December 2016; Revised 12 April 2017; Accepted 3 May 2017; Published 10 July 2017

Academic Editor: Vitor Sencadas

Copyright ( 2017 Zhihui Sun et al. This is an open access article distributed under the Creative Commons Attribution License, which permits unrestricted use, distribution, and reproduction in any medium, provided the original work is properly cited.

\begin{abstract}
In this work, polylactic acid (PLA) biocomposites reinforced with short coir fibers were fabricated using a corotating twin-screw extruder and injection molding machine. Short coir fibers were treated by mixed solution including hydrogen peroxide and sodium hydroxide to improve the adhesion between fibers and PLA matrix. The effects of treated coir fiber content (1, 3, 5, and 7 wt\%) on tensile, impact, thermal properties, and surface morphology of PLA biocomposites were investigated. The best impact strength results were obtained for $3 \mathrm{wt} \%$ PLA/treated coir fiber biocomposites, where the impact strength was increased by approximately $28 \%$ compared to the neat PLA. The tensile modulus of PLA biocomposites was increased by increasing the treated coir fiber content. These results were confirmed by morphological structure analysis. Differential scanning calorimetry (DSC) results demonstrated a minor effect of the treated coir fiber on thermal behavior of PLA resin. Thermogravimetry analysis (TGA) demonstrated that the thermal stability of the PLA/treated coir fiber biocomposites was reduced by the incorporation of treated coir fiber.
\end{abstract}

\section{Introduction}

In recent years, more and more researchers have turned their attention toward environmental pollution and limited petroleum resources. One of the solutions to reducing environmental pollution and depleting petrochemical-based plastics is to utilize degradable biomaterials $[1,2]$. PLA is a kind of biocompatible and biodegradable polymer with a wide range of applications. However, its applications are limited by its slow crystallization speed and brittleness to some extent [3-6]. To overcome these disadvantages of PLA, many studies have shown that adding natural fiber such as flax, hemp, jute, and sisal is an effective, useful method to reinforce PLA [7-13].

Coir fiber is selected for this study as it is nontoxic, has low cost, has low density, and is biodegradable. Coir fibers have low cellulose (40-43\%) and hemicellulose $(0.15-0.25 \%)$ contents and a high lignin content (41-45\%) [8, 14]. In addition, coir fiber is also hydrophilic in nature. This characteristic prevents itself from interacting with most hydrophobic polymers, including PLA. Therefore, in order to improve the interfacial bonding between polymer and natural fiber, a lot of treatments are made to modify the surface of the fiber such as alkali, bleaching, acetylation, and steaming. Alkali treatment is one of most widely used methods [10, 1519]. In this process, the lignin, hemicelluloses, pectin, and other impurities in the fiber are dissolved, and the molecular orientation is improved due to a reduction of the rotation angle of the microfibers. The fiber surface becomes rough so that the bonding ability between the fiber and polymer interface is enhanced. Bleaching with hydrogen peroxide has the same effect [16, 20-23].

In this study, coir fibers were chemically pretreated with the mixed solution of hydrogen peroxide and sodium hydroxide to increase their compatibility with the PLA matrix. Then, the mechanical properties and morphology of PLA/treated coir fiber biocomposites (HPCFs) were investigated, comparing with untreated coir fiber reinforced PLA biocomposites. Furthermore, the thermal properties of HPCFs were studied.

\section{Experimental}

2.1. Materials and Fiber Treatments. PLA 4032D pellets with a material density of $1.24 \mathrm{~g} / \mathrm{cm}^{3}$ were purchased from Nature Works LLC, USA. Coir fibers with a fiber diameter in the 
TABLE 1: Biocomposites compositions.

\begin{tabular}{lcccc}
\hline Code & PLA $(w t \%)$ & Coir fibers $(w t \%)$ & Temperature profile $\left({ }^{\circ} \mathrm{C}\right)$ & Extrusion \\
\hline Neat PLA & 100 & 0 & $160,170,180 ; 190 ; 185,180$ & 30 \\
$1 \%$ HPCF & 99 & 1 & $160,170,180 ; 190 ; 185,180$ & 30 \\
$3 \%$ HPCF & 97 & 3 & $160,170,180 ; 190 ; 185,180$ & 30 \\
$5 \%$ HPCF & 95 & 5 & $160,170,180 ; 190 ; 185,180$ & 30 \\
$7 \%$ HPCF & 93 & 7 & $160,170,180 ; 190 ; 185,180$ & 30 \\
\hline
\end{tabular}
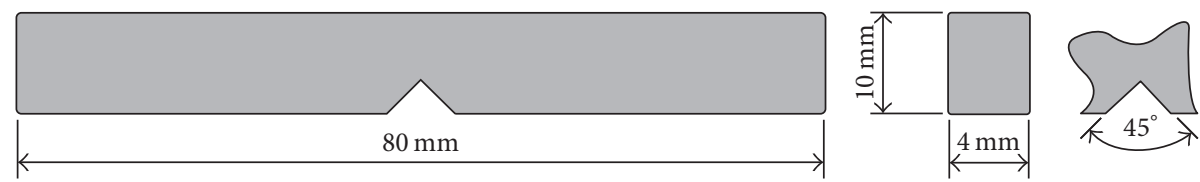

FIGURE 1: Impact sample.

range of $100-450 \mu \mathrm{m}$ were purchased from Tianjin Jia Add Green Products Technology Co., Ltd., China.

The raw coir fibers were chopped into lengths of approximately 4-6 mm and then sieved through a 40-mesh sieve. Short coir fibers were then washed with distilled water for several times and finally dried at $60^{\circ} \mathrm{C}$ for $12 \mathrm{~h}$. The fibers thus obtained were known as untreated coir fiber samples.

Short coir fibers $(250 \mathrm{~g})$ were added to a $1 \mathrm{~L}$ mixed solution containing $160 \mathrm{~mL}(30 \%$; w/w) of hydrogen peroxide and $0.5 \mathrm{~g}$ of sodium hydroxide at $85^{\circ} \mathrm{C}$ and magnetically stirred for $1 \mathrm{~h}$. Subsequently, the soaked coir fibers were washed thoroughly with distilled water and dried in an oven at $60^{\circ} \mathrm{C}$ for $12 \mathrm{~h}[24,25]$. The fibers were treated as treated coir fiber samples.

All neat PLA and coir fiber samples were placed in a desiccator and stored for $24 \mathrm{~h}$.

2.2. Sample Preparation. Blends of PLA and coir fiber were melting extruded. The content of coir fibers in the PLA biocomposites varied between $1,3,5$, and $7 \mathrm{wt} \%$, respectively. This mixture was introduced into a corotating twin-screw extruder with six heating zones with temperatures set at 160 , $170,180,190,185$, and $180^{\circ} \mathrm{C}$ from the feed to the die, according to Table 1 . The diameter of the screws was $18 \mathrm{~mm}$, and the length-to-diameter ratio of the barrel was $30: 1$. The extruded material was cooled in air and then granulated in a cutting mill to produce the composite pellets with dimensions of 4$5 \mathrm{~mm}$. In addition, all obtained pellets were then injected into an injection molding machine (SY-200-1, screw diameter = $22 \mathrm{~mm}$, injection time $=5 \mathrm{~s}$, and cooling time $=20 \mathrm{~s})$ at $180^{\circ} \mathrm{C}$. The PLA biocomposites presented a compact morphology with no evidence of macroscopic pores or voids. These samples were placed in a desiccator at room temperature for at least $48 \mathrm{~h}$ before testing.

2.3. Mechanical Testing. The tensile properties were tested using an RGM-4005 Electronic Tensile Machine (Shenzhen Instrument Co., Ltd.). The sample dimensions were $150 \times 20 \times$ $4 \mathrm{~mm}$, and the sample was in a dog bone shape. A tensile speed of $5 \mathrm{~mm} / \mathrm{min}$ was adopted during the experiment. Tensile strength of neat PLA and PLA biocomposites was carried out in general accordance with China's National Standard test (GB/T 1040-2006).

Notched Charpy Impact Strength tests were carried out on an XCJ-40 impact tester (Chengde Jinjian Testing Instrument Co., Ltd.). The V-notch shape was prepared as shown in Figure 1. The dimensions of the specimens were $80 \times 10 \times$ $4 \mathrm{~mm}$. The impact strength of neat PLA and PLA biocomposites was carried out in general accordance with China's National Standard test (GB/T 1043-2008).

All the tests were performed at room temperature and over five specimens were used for each material batch to ensure good testing reproducibility.

2.4. Scanning Electron Microscopy (SEM). Both the surfaces of coir fibers and the fractured surfaces of the impact specimens, subjected to sputter-coating with platinum, were characterized by Field Emission Scanning Electron Microscopy (FESEM), using Hitachi SU8020 at $15 \mathrm{kV}$.

2.5. Dynamic Mechanical Analysis (DMA). The storage modulus $\left(E^{\prime}\right)$ and loss factor $(\tan \delta)$ of the neat PLA and biocomposite specimens were measured as a function of temperature ( -50 to $150^{\circ} \mathrm{C}$ ) using a Q800 DMA instrument equipped with a 3-point bending fixture at a frequency of $1 \mathrm{~Hz}$ and a constant heating rate of $3^{\circ} \mathrm{C} / \mathrm{min}$. In addition, the dimensions of the specimens were $60 \times 10 \times 4 \mathrm{~mm}$.

2.6. Differential Scanning Calorimetry (DSC). The thermal properties of the neat PLA and HPCF specimens were measured with a Mettler Toledo DSC1 Star. The heating temperature was ramped from 30 to $210^{\circ} \mathrm{C}$ at a rate of $10^{\circ} \mathrm{C} / \mathrm{min}$. All these experiments were carried out in a nitrogen atmosphere. The associated thermal parameters, such as the glass transition temperature $\left(T_{g}\right)$, cold crystallization temperature $\left(T_{\mathrm{cc}}\right)$, melting temperature $\left(T_{m}\right)$, and heat of fusion $\left(\Delta H_{m}\right)$, were determined from the first heating cycle. The resulting degree of crystallinity $\left(X_{c}\right)$ was calculated based on the following $[26,27]$ :

$$
X_{c}(\%)=\frac{\Delta H_{m}}{\Delta H_{m}^{0}} \times \frac{100 \%}{w}
$$




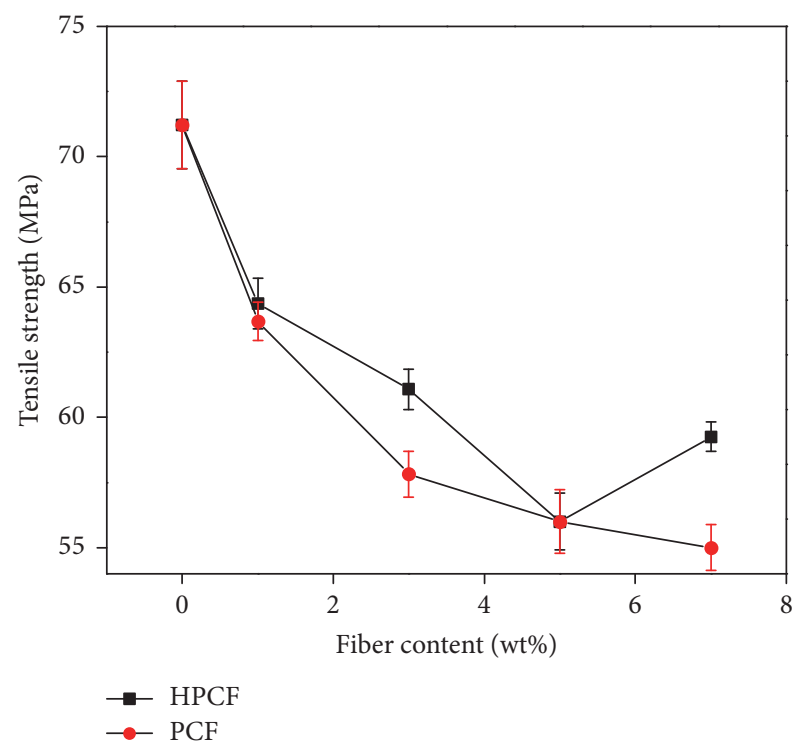

(a)

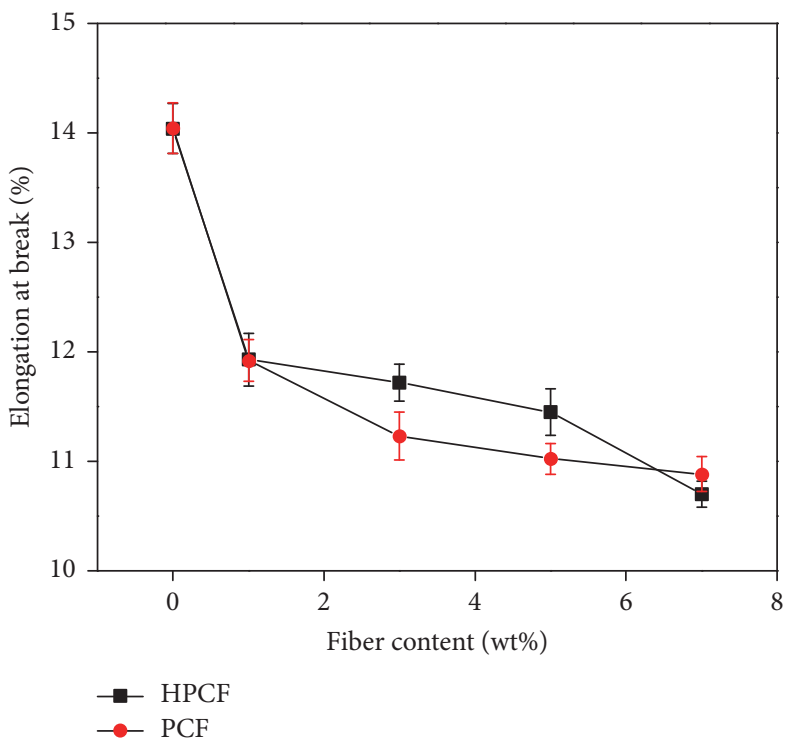

(c)

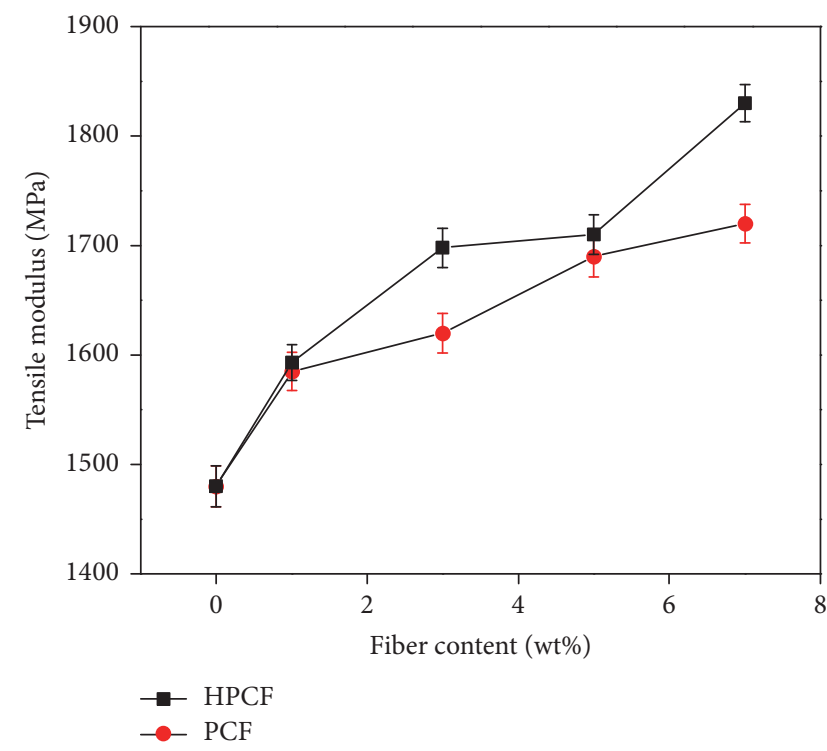

(b)

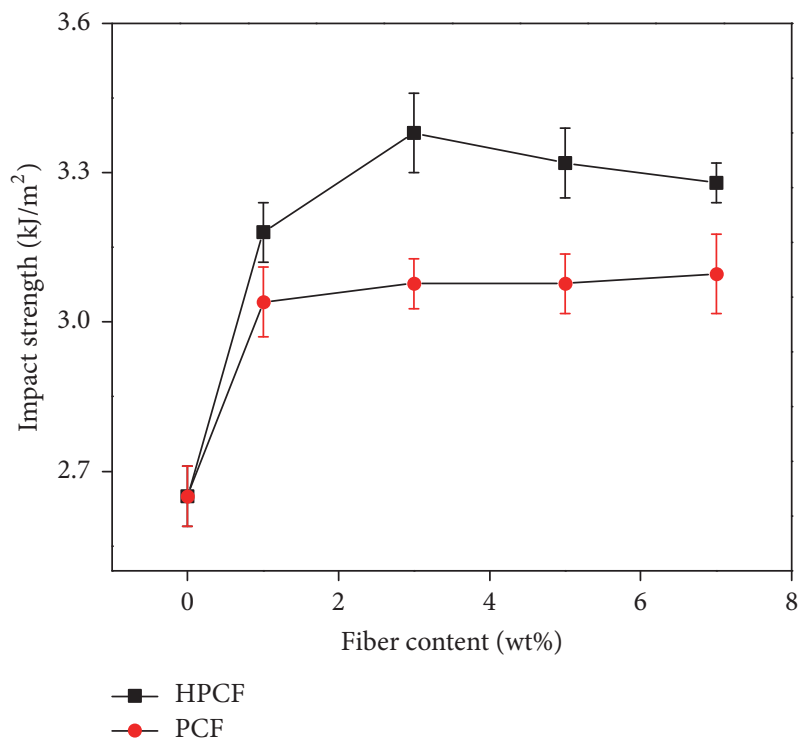

(d)

FIGURE 2: Mechanical properties of PCFs and HPCFs: (a) tensile strength, (b) tensile modulus, (c) elongation at break, and (d) impact strength.

where $\Delta H_{m}^{0}$ is the heat of fusion for a $100 \%$ crystalline PLA material $\left(\Delta H_{m}^{0}=93 \mathrm{~J} / \mathrm{g}\right)$ and $w$ is the weight fraction of the PLA matrices in the biocomposites [28]. The thermal properties of all the specimens were measured in triplicate.

2.7. Thermal Properties. Thermogravimetric analysis (TGA) was performed with a Mettler Toledo GmbH (TGA/ SDTA $851^{\mathrm{e}}$ ) to detect the thermal decomposition of the neat PLA and HPCF specimens. Approximately $6-10 \mathrm{mg}$ of the TGA samples was examined from 30 to $500^{\circ} \mathrm{C}$ at a heating ramp rate of $10^{\circ} \mathrm{C} / \mathrm{min}$ under a nitrogen flow of $200 \mathrm{~mL} / \mathrm{min}$.

\section{Results and Discussion}

3.1. Mechanical Properties. The variation of mechanical properties of both PLA/untreated coir fiber biocomposites (PCFs) and HPCFs with different coir fiber content from 1 to $7 \%$ is shown in Figure 2. Figure 2(a) shows that the tensile strength of PLA biocomposites is lower than that of neat PLA and decreases continuously with increasing fiber content regardless of fiber treatment. As it is known, coir fiber is low tensile strength compared to other fibers, which has an adverse effect on the improvement of tensile strength of PLA biocomposites due to the inherent rigidity of the coir fiber. Another possible explanation can be that tensile strength of PLA biocomposites can be predominantly influenced by the coir fiber agglomeration at higher fiber content, which results in poor stress transfer across the interface [29]. Overall, the strength levels of PCFs are inferior to their counterparts with HPCFs, which is in good agreement with the previous literature [21]. The result indicates that the weak adhesion between untreated coir fibers and the PLA matrix results 


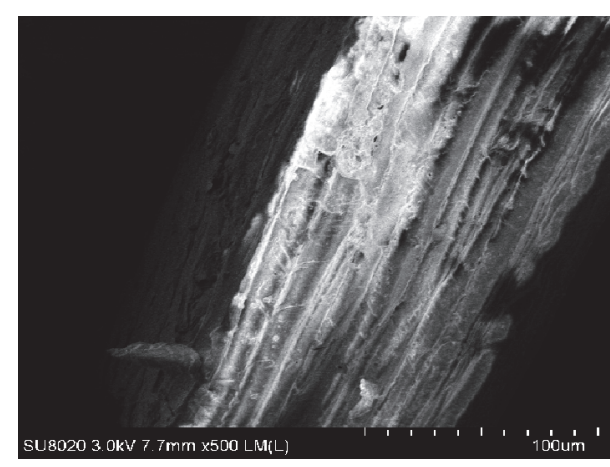

(a)

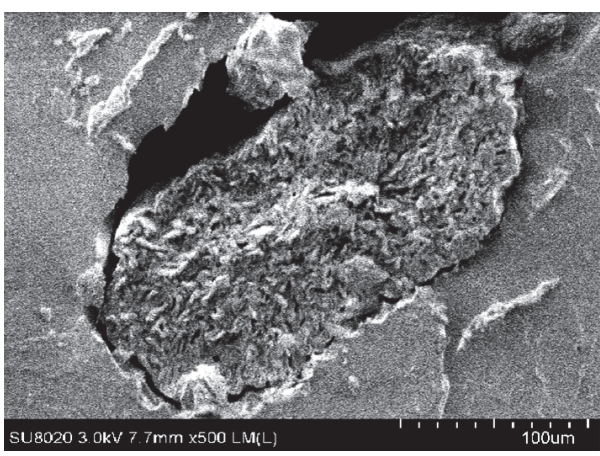

(c)

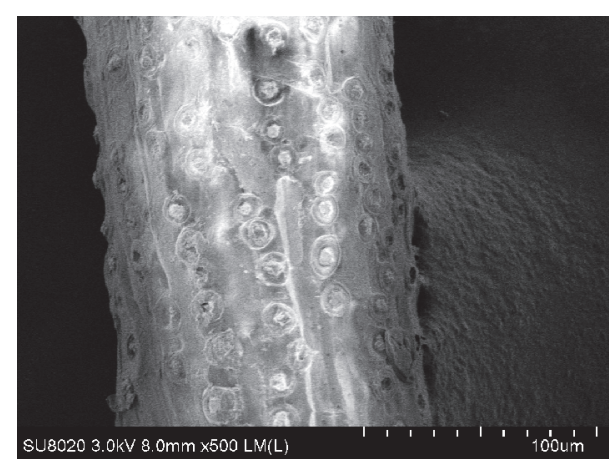

(b)

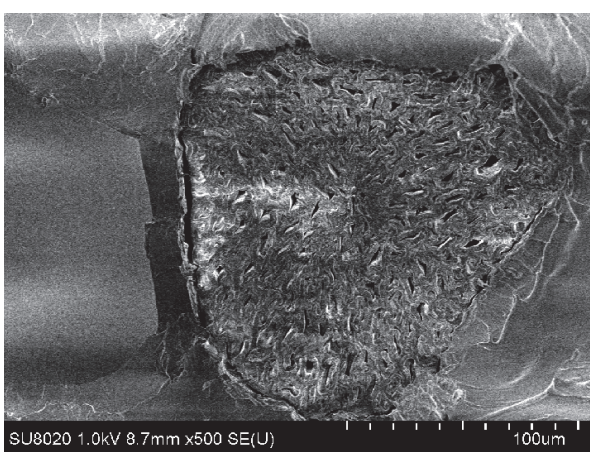

(d)

FiguRE 3: SEM micrographs of (a) untreated coir fibers, (b) treated coir fibers, (c) 3\% PCF, and (d) 3\% HPCF.

in the stress not being transferred from the matrix to the stronger fiber [30]. Figure 2(b) shows that the tensile modulus of PLA biocomposites is higher than that of neat PLA due to the reducing of chain mobility in more filler content, which allows high stiffness in its composites [31]. And the tensile modulus of HPCFs is higher than that of PCFs at the same fiber content. The result indicates that alkali and hydrogen peroxide treatment promoted adequate compatibility and wettability between fiber and PLA matrix due to removing pectin and lignin from treated coir fiber [32].

On the other hand, the PCFs and HPCFs also show a reduction in their elongation at break values in comparison to neat PLA as shown in Figure 2(c). This result indicates that the biocomposites are more brittle than neat PLA mainly owing to the well-known rigid reinforcement nature of coir fiber [25]. And the elongation at break values of PCFs and HPCFs decreases with increasing fiber content. This behavior is probably associated with uneven aligning of coir fibers with PLA matrix [32]. Furthermore, the elongation at break values of HPCFs is higher than that of PCFs at the same fiber content. The mixed solution treatment often leads to the removal of the lignin and pectin from coir fibers, which results in relatively increasing the cellulose content. So the flexibility and elasticity of coir fiber are improved [25].

The impact strengths of HPCFs and PCFs at different coir fiber content are shown in Figure 2(d). The impact strength of coir fiber reinforced PLA biocomposites increases at all concentrations, as expected. This indicates that the addition of coir fiber is effective to increase the impact absorbance of the biocomposite materials [33]. And it is found that the impact strength of HPCFs is always higher than the value of PCFs at the same fiber content. It is known that the interfacial bonding strength between matrix and fiber affects the impact property of PLA biocomposites. The result reveals that the interfacial bonding between treated fiber and PLA matrix is better than that between untreated fiber and PLA matrix. In addition, impact energy is dissipated by debonding, fiber and/or matrix fracture and fiber pull-out [34]. The treated coir fiber at fiber content $3 \%$ by weight increases the impact strength by $27.55 \%$ compared to the neat PLA. With further increase in treated fibers content (i.e., at 5\%) the impact strength of HPCFs decreases due to agglomeration of fiber.

3.2. Morphological Structures. Figures 3(a) and 3(b) show the micromorphology of coir fiber surface. As shown in Figure 3(a), the untreated coir fibers exhibit smooth surface due to the presence of wax/pectin and other surface impurities [35]. By comparison, many holes and cracks are discovered on the treated coir fiber surface, as shown in Figure 3(b). This result proves that the mixed solution treatment of coir fiber is efficient for removing these impurities and improves the surface roughness. The increased surface roughness of treated coir fiber would likely result in more mechanical interlocking between fibers with matrix. In addition, the colour change of coir fiber from brown to yellowish brown is observed due to removal of lignin, wax, and fatty [18]. 

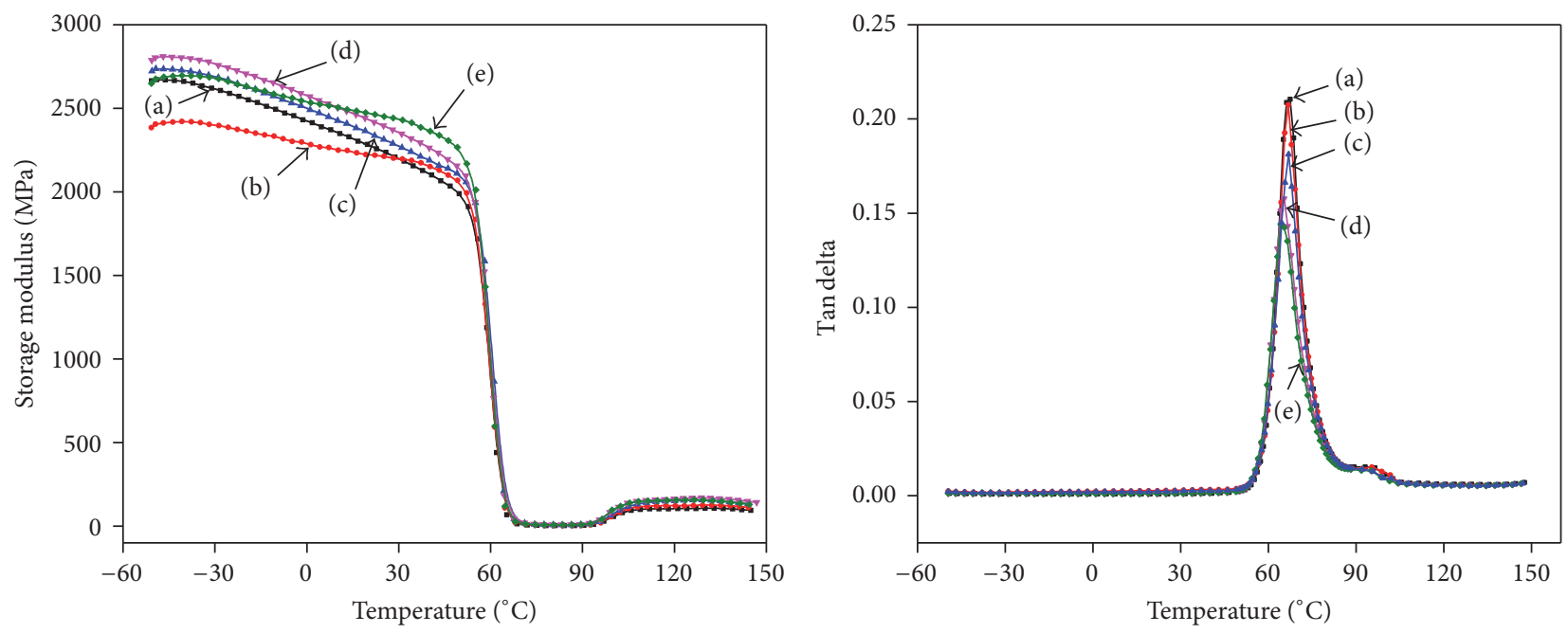

Figure 4: DMA curves of (a) neat PLA, (b) 1\% HPCF, (c) 3\% HPCF, (d) 5\% HPCF, and (e) 7\% HPCF.

Figures 3(c) and 3(d) show the micromorphology of impact fractured surfaces of $3 \%$ PCF and $3 \%$ HPCF, respectively. As shown in Figure 3(c), the interface between the untreated coir fiber and the PLA matrix is loose because no PLA matrix adhered to the coir fiber surface. Figure 3(d) can be obviously observed that there is smaller interstice between treated coir fiber and PLA matrix and there is more PLA matrix adhered to the surface of treated coir fiber. This shows that the interfacial adhesion is believed to be better improved by the fiber treatment, resulting in impact strength improvement of HPCFs. SEM results are in good agreement with mechanical results.

3.3. DMA Analysis. The plot of storage modulus $\left(E^{\prime}\right)$ against temperature for the neat PLA and HPCFs is shown in Figure 4. The values of $E^{\prime}$ increase with the addition of the treated coir fibers, which suggested better adhesion between the treated fibers and the PLA matrix. All the composites show a sharp decrease in $E^{\prime}$ at approximately $66^{\circ} \mathrm{C}$ due to the glass transition and then a significant increase in the storage modulus above $93^{\circ} \mathrm{C}$. This is a result of the cold crystallization of the amorphous PLA matrix [36]. Although studies have shown the effect of natural fibers as nucleating agents on the crystallization of PLA, they have emphasized the role of interfacial interactions between the treated coir fiber and the matrix. In other words, the rate of crystallization of the PLA is modified by optimizing the interfacial interaction between the fibers and PLA matrix [37].

The peak of $\tan \delta$ decreases rapidly with addition of the coir fibers; this is mainly due to the existence of effective interracial bonding between fiber and matrix. Table 2 shows that $T_{g}$ and $T_{c}$ are slightly shifted to a lower temperature. The HPCFs induce cold crystallization earlier than the neat PLA samples.

3.4. DSC Thermal Analysis. The DSC thermograms and associated thermal parameters for the neat PLA and HPCFs are shown in Figure 5 and Table 3, respectively. With the
TABLE 2: DMA data for PLA and HPCFs.

\begin{tabular}{lccc}
\hline Code & $T_{g}\left({ }^{\circ} \mathrm{C}\right)$ & $T_{c, \text { onset }}\left({ }^{\circ} \mathrm{C}\right)$ & $\begin{array}{c}\text { Storage modulus at } 25^{\circ} \mathrm{C} \\
(\mathrm{GPa})\end{array}$ \\
\hline Neat PLA & 67 & 94 & 2.2 \\
1\% HPCF & 66 & 93 & 2.2 \\
$3 \%$ HPCF & 65 & 92 & 2.3 \\
$5 \%$ HPCF & 65 & 92 & 2.4 \\
$7 \%$ HPCF & 64 & 93 & 2.5 \\
\hline
\end{tabular}

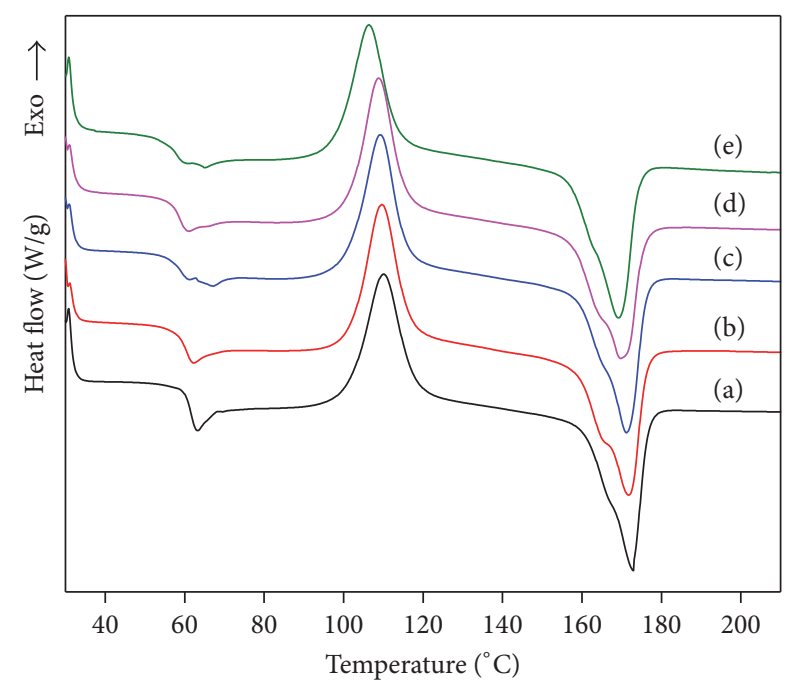

FIGURE 5: DSC thermograms of (a) neat PLA, (b) 1\% HPCF, (c) $3 \%$ HPCF, (d) 5\% HPCF, and (e) 7\% HPCF.

incorporation of treated coir fibers within PLA matrix $T_{g}$ decreases which indicates increased mobility and free volume of the matrix chains by loose packing of filler within the matrix due to poor interaction between the treated coir fibers and PLA matrix [38]. 
TABLE 3: DSC data for PLA and HPCFs.

\begin{tabular}{lccccccccc}
\hline Sample & $T_{g}\left({ }^{\circ} \mathrm{C}\right)$ & $T_{o, c}\left({ }^{\circ} \mathrm{C}\right)$ & $T_{p, c}\left({ }^{\circ} \mathrm{C}\right)$ & $T_{c}\left({ }^{\circ} \mathrm{C}\right)$ & $T_{m 1}\left({ }^{\circ} \mathrm{C}\right)$ & $T_{m 2}\left({ }^{\circ} \mathrm{C}\right)$ & $\Delta H_{c, \text { PLA }}(\mathrm{J} / \mathrm{g})$ & $\Delta H_{m, \mathrm{PLA}}(\mathrm{J} / \mathrm{g})$ & $X_{c}(\%)$ \\
\hline Neat PLA & 63 & 101 & 118 & 110 & 159 & 177 & 4.21 & 5.97 \\
1\% HPCF & 62 & 102 & 117 & 110 & 159 & 176 & 3.71 & 5.42 \\
$3 \%$ HPCF & 61 & 100 & 116 & 109 & 159 & 176 & 4.16 & 5.89 \\
$5 \%$ HPCF & 61 & 101 & 116 & 109 & 158 & 176 & 4.00 & 4.90 & 4.96 \\
$7 \%$ HPCF & 61 & 97 & 114 & 107 & 157 & 175 & 4.09 & 5.43 \\
\hline
\end{tabular}
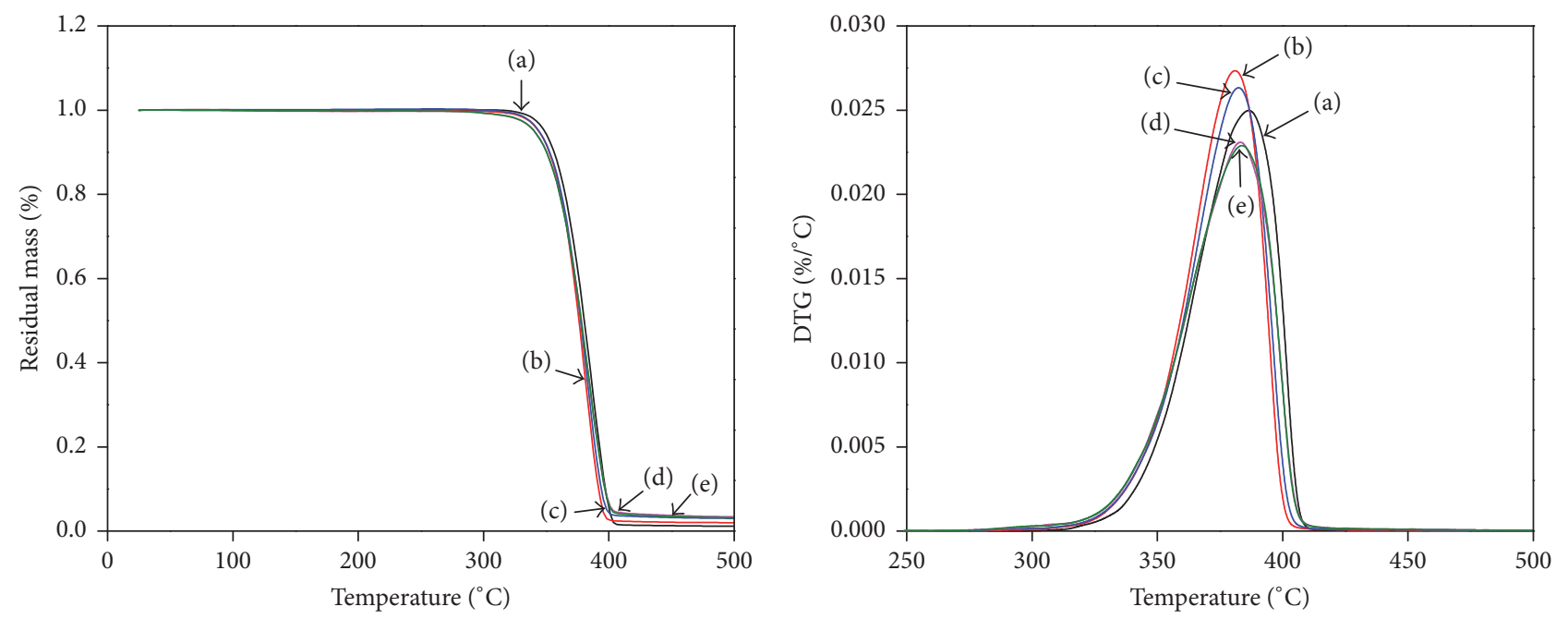

Figure 6: TGA and DTGA curves of (a) neat PLA, (b) 1\% HPCF, (c) 3\% HPCF, (d) 5\% HPCF, and (e) 7\% HPCF.

TABLE 4: TGA data for PLA and HPCFs.

\begin{tabular}{lcc}
\hline Code & $T_{\max }\left({ }^{\circ} \mathrm{C}\right)$ & Total weight loss at $500^{\circ} \mathrm{C}(\%)$ \\
\hline Neat PLA & 388 & 99 \\
$1 \%$ HPCF & 382 & 98 \\
$3 \%$ HPCF & 382 & 97 \\
$5 \%$ HPCF & 382 & 97 \\
$7 \%$ HPCF & 385 & 97 \\
\hline
\end{tabular}

$T_{m}$ of the HPCFs modest decreases compared to that of neat PLA. The degree crystallinity has a decreasing tendency with the fiber content increasing. This may be attributed to the increase in amorphosity of the HPCFs [39].

In addition, $T_{c}$ of the HPCFs decreases considerably from 110 to $107^{\circ} \mathrm{C}$, as opposed to that of the neat PLA ( $T_{c}$ $\left.=110^{\circ} \mathrm{C}\right)$. This confirms that the treated coir fibers create favorable conditions for PLA crystallization and thus increase the crystallization rate. Due to an effective nucleating effect of treated coir fibers, $X_{c}$ of the HPCFs is improved with increasing the coir fibers content [39].

3.5. TGA Results. The TGA and DTG curves of the PLA and HPCFs are shown in Figure 6 and summarized in Table 4. The peak temperature of weight loss of HPCFs shifted to the lower temperature region. The thermal stability of HPCFs decreased with increasing treated coir fiber content which can be clearly seen in Table 4 . Evidently, increasing the treated coir fiber content enables the decrease in thermal stability of HPCFs due to the lower thermal stability of the coir fiber [25].

\section{Conclusions}

The mechanical and thermal properties of neat PLA and HPCFs were investigated. The tensile strength and elongation at break of HPCFs decreased with the increasing of treated coir fiber content. However the tensile modulus and impact strength of HPCFs increased with fiber content. Thus the interfacial adhesion between PLA and treated coir fiber was believed to be improved by the pretreatment of fiber. This result was supported by SEM analyses. The DMA results showed that the treated coir fiber reinforced biocomposites have higher storage modulus resulting in significantly improved stiffness. Crystallinity of HPCFs increased by introduction of treated coir fibers. The total weight loss of $\mathrm{HPCF}$ reduced at $500^{\circ} \mathrm{C}$.

\section{Conflicts of Interest}

The authors declare that they have no conflicts of interest.

\section{Acknowledgments}

The authors gratefully acknowledge the support from Key Projects in the National Science \& Technology Pillar Program during the Twelfth Five-Year Plan Period (2011BAD24B01-3), the Harbin Science \& Technology Research and Development 
Funds (2014RFXXJ057), and the Research Team Project of Harbin University of Commerce (2016TD005).

\section{References}

[1] T. Gurunathan, S. Mohantyand, and S. K. Nayak, "A review of the recent developments in biocomposites based on natural fibres and their application perspectives," Composites Part A Applied Science and Manufacturing, vol. 77, pp. 1-25, 2015.

[2] K. L. Pickering, M. G. A. Efendy, and T. M. Le, "A review of recent developments in natural fibre composites and their mechanical performance," Composites Part A: Applied Science and Manufacturing, vol. 83, pp. 98-112, 2016.

[3] X. Li, C. Guo, X. Liu et al., "Impact behaviors of poly-lactic acid based biocomposite reinforced with unidirectional highstrength magnesium alloy wires," Progress in Natural Science: Materials International, vol. 24, no. 5, pp. 472-478, 2014.

[4] H. Liu and J. Zhang, "Research progress in toughening modification of poly(lactic acid)," Journal of Polymer Science, Part B: Polymer Physics, vol. 49, no. 15, pp. 1051-1083, 2011.

[5] R. L. Yu, L. S. Zhang, Y. H. Feng, R. Y. Zhangand, and J. Zhu, "Improvement in toughness of polylactide by melt blending with bio-based poly(ester)urethane," Chinese Journal of Polymer Science, vol. 32, pp. 1099-1110, 2014.

[6] V. Ojijoand and S. S. Ray, "Super toughened biodegradable polylactide blends with non-linear copolymer interfacial architecture obtained via facile in-situ reactive compatibilization," Polymer, vol. 80, pp. 1-17, 2015.

[7] L. Yan, N. Chouw, and K. Jayaraman, "Flax fibre and its composites-a review," Composites Part B: Engineering, vol. 56, pp. 296-317, 2014.

[8] M. P. M. Dicker, P. F. Duckworth, A. B. Baker, G. Francois, M. K. Hazzardand, and P. M. Weaver, "Green composites: a review of material attributes and complementary applications," Composites Part A Applied Science and Manufacturing, vol. 56, pp. 280-289, 2014.

[9] S. Siengchin, "Reinforced flax mat/modified polylactide (PLA) composites: Impact, thermal, and mechanical properties," Mechanics of Composite Materials, vol. 50, no. 2, pp. 257-266, 2014.

[10] X. Xia, W. Liu, L. Zhou, Z. Hua, H. Liu, and S. He, "Modification of flax fiber surface and its compatibilization in polylactic acid/flax composites," Iranian Polymer Journal (English Edition), vol. 25, no. 1, pp. 25-35, 2016.

[11] K. Ahtiainen, L. Sippola, M. Nurminen et al., "Effects of chitosan and bioactive glass modifications of knitted and rolled polylactide-based 96/4 L/D scaffolds on chondrogenic differentiation of adipose stem cells," Journal of Tissue Engineering and Regenerative Medicine, vol. 9, no. 1, pp. 55-65, 2012.

[12] K. C. Cheng, Y. H. Lin, W. Guo et al., "Flammability and tensile properties of polylactide nanocomposites with short carbon fibers," Journal of Materials Science, vol. 50, pp. 1605-1612, 2015.

[13] M. Thunga, K. Chen, D. Grewell, and M. R. Kessler, "Biorenewable precursor fibers from lignin/polylactide blends for conversion to carbon fibers," Carbon, vol. 68, pp. 159-166, 2014.

[14] M. A. Al-Maadeedand and S. Labidi, "4-Recycled polymers in natural fibre-reinforced polymer composites," Natural Fibre Composites, pp. 103-114, 2014.

[15] M. M. Kabir, H. Wang, K. T. Lau, and F. Cardona, "Chemical treatments on plant-based natural fibre reinforced polymer composites: an overview," Composites Part B: Engineering, vol. 43, no. 7, pp. 2883-2892, 2012.
[16] Y. Dong, A. Ghataura, H. Takagi, H. J. Haroosh, A. N. Nakagaitoand, and K. T. Lau, "Polylactic acid (PLA) biocomposites reinforced with coir fibres: evaluation of mechanical performance and multifunctional properties," Composites Part A Applied Science Manufacturing, vol. 63, pp. 76-84, 2014.

[17] F. Shukor, A. Hassan, M. S. Islam, M. Mokhtarand, and M. Hasan, "Effect of ammonium polyphosphate on flame retardancy, thermal stability and mechanical properties of alkali treated kenaf fiber filled PLA biocomposites," Materials and Design, vol. 54, pp. 425-429, 2014.

[18] T. P. T. Tran, J.-C. Bénézet, and A. Bergeret, "Rice and Einkorn wheat husks reinforced poly(lactic acid) (PLA) biocomposites: effects of alkaline and silane surface treatments of husks," Industrial Crops Products, vol. 58, pp. 111-124, 2014.

[19] A. Orue, A. Jauregi, U. Unsuain, J. Labidi, A. Eceiza, and A. Arbelaiz, "The effect of alkaline and silane treatments on mechanical properties and breakage of sisal fibers and poly(lactic acid)/sisal fiber composites," Composites Part A: Applied Science and Manufacturing, vol. 84, pp. 186-195, 2016.

[20] J. Rout, M. Misra, S. S. Tripathy, S. K. Nayak, and A. K. Mohanty, "The influence of fibre treatment of the performance of coirpolyester composites," Composites Science and Technology, vol. 61, no. 9, pp. 1303-1310, 2001.

[21] M. A. Salam, "Effect of hydrogen peroxide bleaching onto sulfonated jute fiber," Journal of Applied Polymer Science, vol. 99, no. 6, pp. 3603-3607, 2006.

[22] G. P. Otto, M. P. Moisés, G. Carvalho et al., "Mechanical properties of a polyurethane hybrid composite with natural lignocellulosic fibers," Composites Part B Engineering, vol. 110, pp. 459465, 2017

[23] S. L. Fávaro, M. S. Lopes, A. G. V. D. C. Neto, R. R. de Santana, and E. Radovanovic, "Chemical, morphological, and mechanical analysis of rice husk/post-consumer polyethylene composites," Composites Part A: Applied Science Manufacturing, vol. 41, no. 1, pp. 154-160, 2010.

[24] H. Zou, L. Wang, H. Gan, and C. Yi, "Effect of fiber surface treatments on the properties of short sisal fiber/poly(lactic acid) biocomposites," Polymer Composites, vol. 33, no. 10, pp. 16591666, 2012.

[25] Y. Dong, A. Ghataura, H. Takagi, H. J. Haroosh, A. N. Nakagaito, and K.-T. Lau, "Polylactic acid (PLA) biocomposites reinforced with coir fibres: evaluation of mechanical performance and multifunctional properties," Composites Part A: Applied Science and Manufacturing, vol. 63, pp. 76-84, 2014.

[26] Y. Dong, D. Chaudhary, H. Haroosh, and T. Bickford, "Development and characterisation of novel electrospun polylactic acid/tubular clay nanocomposites," Journal of Materials Science, vol. 46, no. 18, pp. 6148-6153, 2011.

[27] A. P. Mathew, K. Oksman, and M. Sain, "The effect of morphology and chemical characteristics of cellulose reinforcements on the crystallinity of polylactic acid," Journal of Applied Polymer Science, vol. 101, no. 1, pp. 300-310, 2006.

[28] C. Nyambo, A. K. Mohanty, and M. Misra, "Polylactide-based renewable green composites from agricultural residues and their hybrids," Biomacromolecules, vol. 11, no. 6, pp. 1654-1660, 2010.

[29] W. Sujaritjun, P. Uawongsuwan, W. Pivsa-Artand, and H. Hamada, "Mechanical property of surface modified natural fiber reinforced PLA biocomposites," Energy Procedia, vol. 34, pp. 664-672, 2013.

[30] M. F. Rosa, B.-S. Chiou, E. S. Medeiros et al., "Effect of fiber treatments on tensile and thermal properties of starch/ethylene 
vinyl alcohol copolymers/coir biocomposites," Bioresource Technology, vol. 100, no. 21, pp. 5196-5202, 2009.

[31] S. T. Sam, H. Ismail, and Z. Ahmad, "Soil burial of polyethyleneg-(maieic anhydride) compatibilised LLDPE/Soya powder blends," Polymer - Plastics Technology and Engineering, vol. 50, no. 8, pp. 851-861, 2011.

[32] B. Asaithambi, G. Ganesan, and S. Ananda Kumar, "Biocomposites: development and mechanical characterization of banana/sisal fibre reinforced poly lactic acid (PLA) hybrid composites," Fibers and Polymers, vol. 15, no. 4, pp. 847-854, 2014.

[33] E. Jayamani, S. Hamdan, M. R. Rahman, M. K. B. Bakri, and A. Kakar, "An investigation of sound absorption coefficient on sisal fiber poly lactic acid bio-composites," Journal of Applied Polymer Science, vol. 132, no. 34, Article ID 42470, 2015.

[34] W. Nuthong, P. Uawongsuwan, W. Pivsa-Artand, and H. Hamada, "Impact property of flexible epoxy treated natural fiber reinforced PLA composites," Energy Procedia, vol. 34, pp. 839-847, 2013.

[35] S. Oza, "Dissertations and Theses - Gradworks," 2013.

[36] E. Nassiopoulos and J. Njuguna, "Thermo-mechanical performance of poly(lactic acid)/flax fibre-reinforced biocomposites," Materials Design, vol. 66, pp. 473-485, 2015.

[37] P. Pan, B. Zhu, W. Kai, S. Serizawa, M. Iji, and Y. Inoue, "Crystallization behavior and mechanical properties of biobased green composites based on poly(L-lactide) and kenaf fiber," Journal of Applied Polymer Science, vol. 105, no. 3, pp. 15111520, 2007.

[38] P. J. Jandas, S. Mohanty, S. K. Nayak, and H. Srivastava, "Effect of surface treatments of banana fiber on mechanical, thermal, and biodegradability properties of PLA/banana fiber biocomposites," Polymer Composites, vol. 32, no. 11, pp. 1689-1700, 2011.

[39] J. S. Carpenter, C. Bai, J. P. Escobedo et al., Characterization of Minerals, Metals, and Materials 2015, John Wiley \& Sons, Inc., Hoboken, NJ, USA, 2015. 

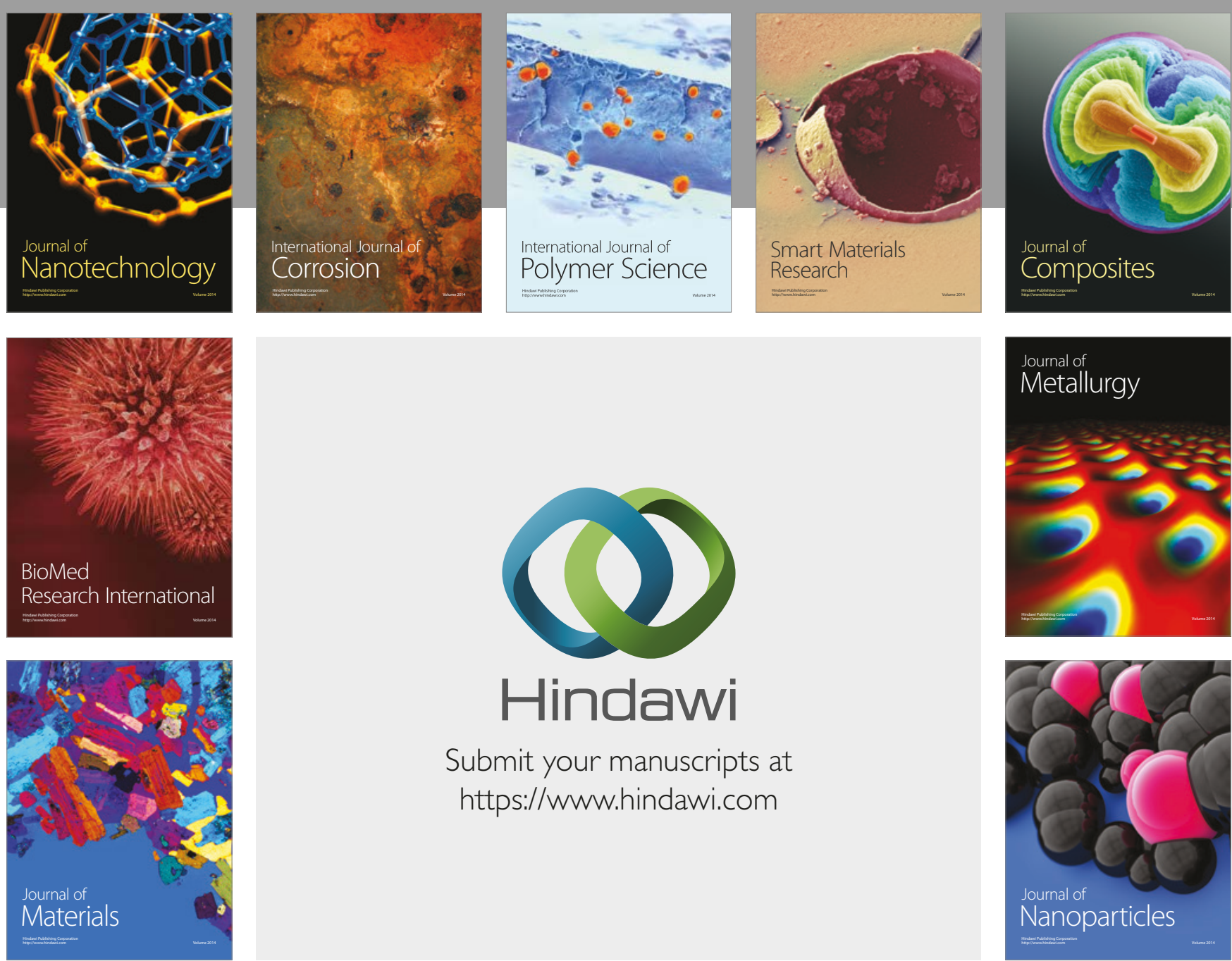

\section{Hindawi}

Submit your manuscripts at

https://www.hindawi.com
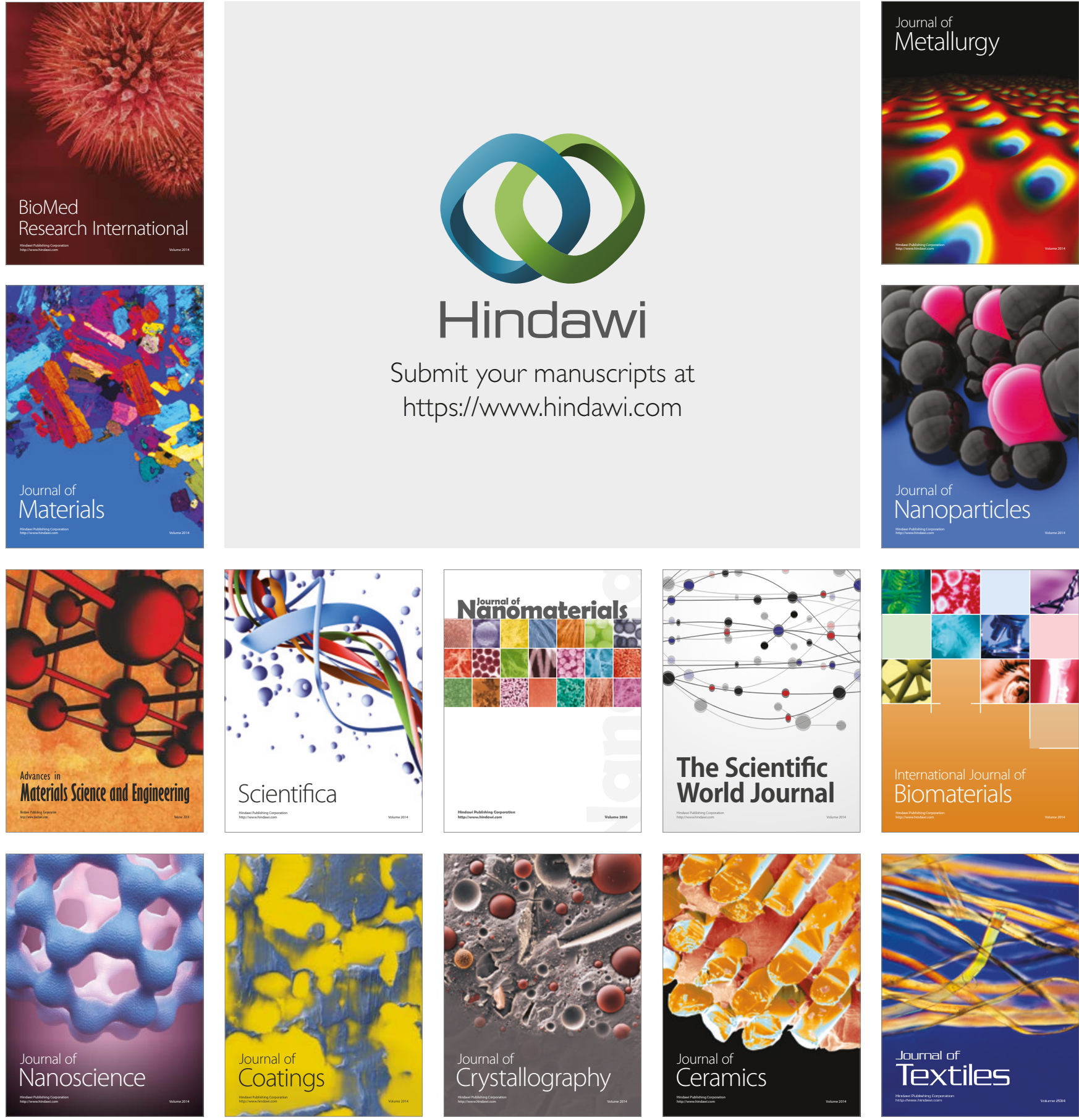

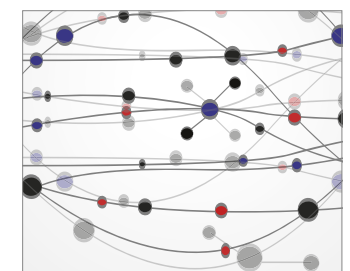

The Scientific World Journal
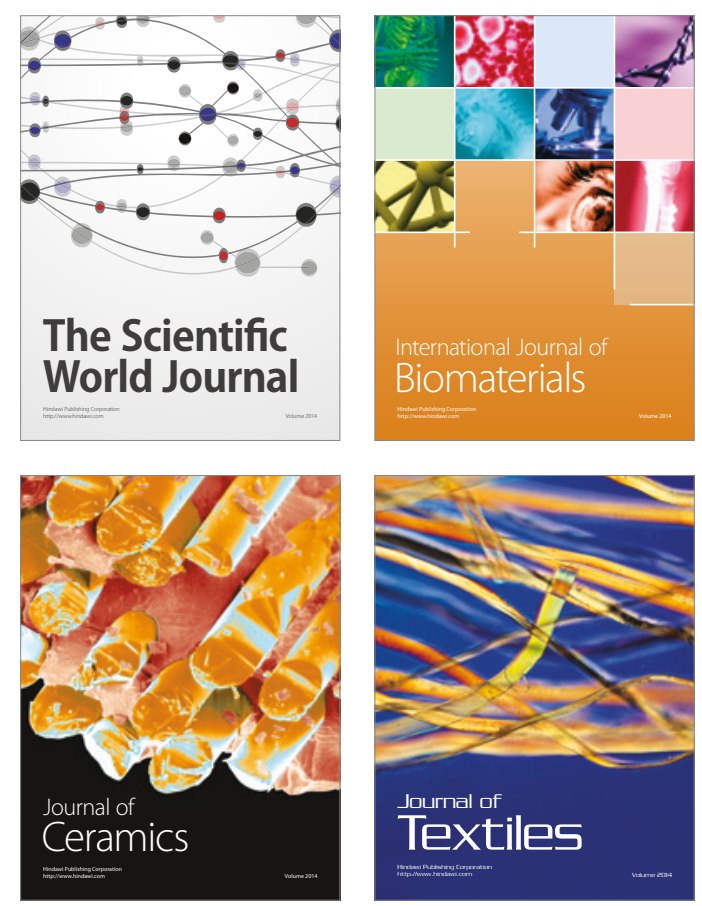